\title{
Catching English: \\ Constructing language choice between Tagalog-English bilingual siblings
}

\author{
Nicole Denise Salvador, Elena Nicoladis \\ elenan@ualberta.ca \\ Anna Patricia Nicole Diego \\ UNIVERSITY OF ALBERTA
}

\begin{abstract}
In multicultural Canada, preserving heritage languages (HLs) is an issue for many immigrant families. Many parents want to maintain their $H L$ with their children, but do not necessarily speak it consistently at home. In addition, older siblings may start speaking the HL less once they start school. This study examined the language choice among TagalogEnglish bilingual siblings in an English-majority setting. We expected to see greater use of English when at least one of the siblings was in school and when pretending to interact in public settings (like schools or restaurants) rather than private. The results showed that the children spoke mostly English regardless of whether they (or their sibling) were in school and regardless of context (public vs. private). We discuss possible reasons for these children's high use of English.
\end{abstract}

Key words: heritage languages, siblings, bilingual first language acquisition, language choice, code-switching

\section{Résumé}

$A u$ Canada multiculturel, le maintien des langues patrimoniales (LP) représente un enjeu important pour les familles immigrantes. De nombreux parents aimeraient maintenir la $L P$ avec leurs enfants mais ne la parlent pas d'une manière assidue à la maison. De plus, il arrive que les frères et les sœurs ainés parlent moins la LP lorsqu'ils commencent l'école. Cette étude examine le choix de langues entre frères et sœurs bilingues (tagalog-anglais) dans un milieu majoritairement anglais. Nous nous attendions à ce que les enfants parlent plus anglais à partir du moment où au moins l'un d'entre eux était entré à l'école et quand ils s'imaginaient dans des situations publiques (comme à l'école ou à un restaurant) plutôt que lors de situations privées. Les résultats ont pourtant montré que la plupart du temps les enfants choisissaient l'anglais plutôt que le tagalog, 
même s'ils n'avaient pas encore commencé l'école (ou avaient un frère ou une sœur à l'école) et indépendamment du contexte (public vs. privé). Nous discutons certaines explications quant à la préférence pour l'anglais de ces enfants.

Mots-clés : langues patrimoniales, fratrie, acquisition de langue(s) maternelle(s) en contexte bilingue, choix langagiers, alternance codique

Canada has become increasingly multicultural due to the influx of immigrants over the years. In Alberta, about 18-20\% of the population is made up of immigrants (Statistics Canada, 2013), many speaking a language other than English (the majority language in Alberta). Heritage languages (HLs) can sometimes be lost in a single generation (Nagpal \& Nicoladis, 2010). Part of the reason for such rapid loss is that despite their positive attitudes towards maintaining the $\mathrm{HL}$, parents provide little opportunity for their children to practice their HL (Nagpal \& Nicoladis, 2010). Birth order may play a role in HL proficiency: first-born children are usually the most fluent in the HL (BarronHauwaert, 2011; Fantini, 1985; Obied, 2009). The purpose of the present study was to explore two factors that might contribute to bilingual children's language choice when speaking with siblings: 1 ) whether one child was already in school and 2) the language evoked by the context.

Much of the previous work on bilingual children's language choice has focused on parent-child interactions (Chan \& Nicoladis, 2010; Deuchar \& Quay, 2001; Paradis \& Nicoladis, 2007), often in families practicing a one-parent, one-language approach (Barron-Hauwert, 2011; Genesee, Nicoladis, \& Paradis, 1995; Kopeliovich, 2013). There is growing recognition that language choice within families is not determined by parents alone (Azmitia \& Hesser, 1993; Barron-Hauwaert, 2011; Barton \& Tomasello, 1994; Hoff, 2006; Hughes \& Dunn, 2007; King, Fogle, \& Terry, 2008; Quay \& Montanari, 2016). Children who hear more than one language sometimes use a different language than the one used by their parent(s), commonly the dominant language of the community (Barron-Hauwaert, 2011; Chevalier, 2055; Paradis \& Nicoladis, 2007).

One potential motivation to prefer the dominant language of the community is siblings. Older siblings are agents of enculturation to the developing child or substitute caregivers when parents are not around (Dunn, 1983). Older siblings can act as a bridge between the larger community and younger siblings (Mannle \& Tomasello, 1987; see also Berko-Gleason 1975, for similar reasoning about fathers). Siblings encourage turn-taking and extension of pretend play, which help improve the pragmatic skills of the younger child (Barton \& Tomasello, 1994; Mannle \& Tomasello, 1987). One study found that older siblings, unlike peers, provided unique and more detailed problem-solving strategies that aided the younger child's cognitive development (Azmitia \& Hesser, 
1993). In a similar way, studies have shown that sibling relationships also predict the likelihood of children forming friendships as siblings offer more complex pretend play that essentially foster the ability to differentiate one's own perspectives from another (Hughes \& Dunn, 2007). These depths in interactions are not evident in peer relationships because even before children meet their peers, it seems that they first 'practice' social skills with their older siblings, preparing them for their future interactions (Dunn, 1983; Gregory 2001; Hughes \& Dunn, 2007; McHale, Updegraff, \& Whiteman, 2012).

In the context of bilingual families, some studies have shown that older siblings influence the language choice of their younger siblings (Barron-Hauwert, 2011; Fantini, 1985; Obied, 2009; Parada, 2013). This influence is particularly striking when an older sibling starts school in the majority language of the community (Bridges \& Hoff, 2014; Jia, Chen, Kim, Chan, \& Jeung, 2014). For example, Bridges and Hoff (2014) looked at the influence of school transition of older siblings on the language preference of the younger children within Spanish-English bilingual families in the United States. After accounting for the family's linguistic environment and the children's fluency in both languages, they found that school-age siblings spoke more English (the majority language of the community) with their preschool siblings. Furthermore, the presence of school-age siblings also increased the likelihood of mothers speaking English to the preschool siblings (Bridges \& Hoff, 2014). These results can help explain why there are often birth order effects in bilingual families, with the first-borns usually more proficient in a HL than later-born children (BarronHauwaert, 2011; Bridges \& Hoff, 2014; Fantini, 1985; Obied, 2009). Indeed, Bridges and Hoff (2014) found that children without siblings were more fluent in their HL (Spanish) than children with siblings.

In the present study, we expected to replicate the effect of school transition on siblings' language choice. That is, we expected that sibling pairs with at least one sibling in school would speak more English (the majority language of the community) than two preschool siblings.

A secondary purpose of this study was to explore the possible role of context on siblings' language choice. Grosjean (2016) proposed the Complementarity Principle, arguing that bilinguals usually choose the language most suitable in certain domains of conversations. For example, when a school uses English as the medium of instruction, English is likely to be an appropriate language to use in this situation. Conversely, if it has been agreed upon in a family that the HL should be used in the home (King et al., 2008), then one should expect to hear more frequent use of the HL during conversations in and about the home. In support of this argument, Vihman (1998) found that two Estonian-English bilingual siblings code-mixed more when talking about intimate topics (e.g., home and cultural community), while they conversed 
more in the dominant language of their community in public domain topics (e.g., school). A distinction between private and public domains has also been noted for the identities of adult children of immigrants, with the heritage culture being more strongly associated with private domains (Noels \& Clément, 2015). In this study, we predicted that the children would use more English in public domains (like schools and restaurants) and more of their HL in private or community-specific domains (like with grandparents and religious celebrations).

In the current study, we examined the language choice of sibling pairs in Tagalog-English bilingual families. This study took place in Edmonton, Alberta, a part of Canada where English is the majority language. To our knowledge, there are no Tagalog preschool or school programs in this community. We included sibling pairs from three groups with regards to having started school: 1) both preschoolers, 2) one school-aged sibling with one preschooler, and 3) both school-aged. We predicted that when at least one sibling was in school, the sibling pairs would speak more English than when both siblings were preschoolers. A second prediction about the children's language choice was related to the domain of conversation (Grosjean, 2016; Vihman, 1998). We expected that when children's conversations concerned public contexts, they would speak more English than when conversing about private or communityspecific events.

\section{Method}

\section{Participants}

This cross-sectional study consisted of 12 pairs of Tagalog-English older siblings (OSB) ( $M=9.5$ years, $S D=2.9$ years, 8 females, 4 males) and younger siblings (YSB) ( $M=6.3$ years, $S D=2.8$ years, 6 females, 6 males). Most of these children were born in Canada while a few of the older siblings were first-generation immigrants. For some analyses, they were categorized according to the following cohort groups: two sibling pairs of preschool age (PP), five sibling pairs with one preschooler and one school-aged sibling (P-S), and five sibling pairs of school-aged children (S-S). Other than the age and languages criteria, family language background was not systematically accounted for given some restrictions on time and nature of recruitment. The participants were recruited through word-of-mouth and posters hung up in churches and community centers. When parents or guardians contacted the researchers to express interest in the study, we scheduled a time and day for their home visit. As an honorarium for their participation, participants received a $\$ 25$ gift card. 


\section{Materials}

We chose six situations to inspire the siblings' conversations. Three of these situations were potentially Tagalog-oriented (i.e., church, grandparents, and Christmas/Pasko), and three English-oriented (i.e., school, store, and restaurant). Tagalog words representing these situations were written on slips of paper and all six slips of paper were put into a jar.

\section{Procedure}

Two native Tagalog-speaking experimenters visited the families' homes. The experimenters spoke primarily Tagalog throughout the visit. Previous research with bilingual children has shown that even preschool children's language choice is sensitive to the language spoken by a stranger (Genesee, Boivin, \& Nicoladis, 1996). We reasoned that by asking the experimenters to speak primarily Tagalog, we would observe typical Tagalog usage in the families. We return to possible effects of the experimenters' language choice below. Parents first signed consent forms, while the experimenters had a warm-up period with the children. The two siblings were asked if they assented to participate; all did so. Once they assented, testing began. The participants were videotaped while they discussed each of the six Tagalog- and English-oriented situations. The order of the situations was random: the participants chose a situation out of the jar. The pairs had two to three minutes to talk about each of them. The total time of videotaped interaction for each sibling pair was approximately 12 to 15 minutes.

\section{Coding}

The participants' speech was transcribed in orthographic words and each utterance was coded for language choice. Five codes of language choice were used (following Genesee et al., 1995): 1) Tagalog-only, 2) English-only, 3) TagalogEnglish mixed, 4) both, and 5) unknown. Utterances in "both" languages were composed of words that could equally be in either Tagalog or English, often interjections (like "oh"). The utterances classified as "unknown" were utterances that were spoken softly or unclearly such that a language category could not be determined. There were few mixed, both, or unknown utterances so our analyses focus on the Tagalog-only and English-only utterances.

\section{Results}

Table 1 summarizes the average (and standard deviation) of English-only and Tagalog-only utterances by the older and younger siblings of all the sibling pairs. For both older and younger children, there was a tendency for a tradeoff in their language choice, such that the more English they spoke, the less 


\section{TABLE 1}

Average/Mean of English-only and Tagalog-only utterances ( $S D$ in parentheses)

\begin{tabular}{lrrrr}
\hline \hline & \multicolumn{2}{c}{ Older sibling } & \multicolumn{2}{c}{ Younger sibling } \\
\hline English & 105.8 & $(65.9)$ & 55.6 & $(39.9)$ \\
Tagalog & 11.6 & $(13.1)$ & 12.4 & $(17.2)$ \\
\hline \hline
\end{tabular}

Tagalog they spoke. For the OSBs, there was a significant negative correlation between the number of English and Tagalog utterances, $r(10)=-.83, p<$ .05 , while there was a moderate but non-significant negative correlation for the YSBs, $r(10)=-.43, p=.16$.

\section{Effect of school transition}

As can be seen in Table 1, the older siblings tended to talk more than the younger siblings. To equate for the differences between children in how much they talked, we calculated the percentage of English-only utterances out of all of each child's utterances. Recall that the children used few utterances that were neither English-only nor Tagalog-only so the denominator of this percentage changed very little whether we included the mixed, both, and unknown utterances or not.

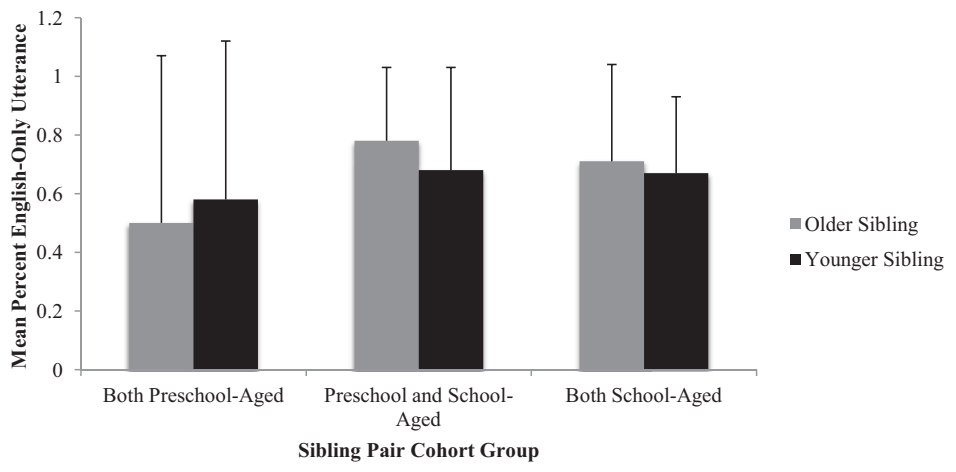

\section{Figure 1}

Mean percent English-only utterance according to cohort group (error bars $=S D)$

Figure 1 shows the mean percentage of English-only utterances by cohort group. Because the language choice of the OSBs and the YSBs is not independent, we tested for the possible cohort effects on two separate one- 
TABLE 2

Mean percent English-only utterances by situation ( $S D$ in parentheses)

\begin{tabular}{llllllc}
\hline \hline Orientation & Situation & \multicolumn{2}{c}{$\begin{array}{c}\text { Older } \\
\text { sibling }\end{array}$} & \multicolumn{2}{c}{$\begin{array}{c}\text { Younger } \\
\text { sibling }\end{array}$} & $\begin{array}{c}\text { Correlation } \\
\text { between siblings }\end{array}$ \\
\hline \multirow{2}{*}{ Tagalog } & Church & $68.2 \%$ & $(39.7 \%)$ & $62.3 \%$ & $(35.0 \%)$ & $.96^{* *}$ \\
& Grandparents & $66.5 \%$ & $(36.5 \%)$ & $51.9 \%$ & $(35.2 \%)$ & $.74^{* *}$ \\
& Christmas & $72.6 \%$ & $(34.1 \%)$ & $71.3 \%$ & $(33.6 \%)$ & $.70^{*}$ \\
\hline \multirow{2}{*}{ English } & School & $72.5 \%$ & $(31.8 \%)$ & $64.2 \%$ & $(41.2 \%)$ & .50 \\
& Store & $70.1 \%$ & $(36.4 \%)$ & $63.0 \%$ & $(30.8 \%)$ & $.75^{* *}$ \\
& Restaurant & $70.4 \%$ & $(26.2 \%)$ & $71.4 \%$ & $(28.3 \%)$ & $.78^{* *}$ \\
\hline \hline
\end{tabular}

$* * p<.01 ; * p<0.05$

way ANOVAs, one with the OSBs and one with the YSBs. The results revealed no significant difference in the percentage of English-only utterances by cohort group either among the OSBs, $F(2,9)=0.49, p=.63$, or the YSBs, $F(2,9)=0.06, p=.93$. The homogeneity of variances for both OSB and YSB was not violated according to Levene's Test, confirming that ANOVA is an appropriate test for this sample. However, it is also worth mentioning that the variability in the PP group was much higher than in the other two groups, as can be seen in Figure 1 as well.

\section{Effect of situation on language choice}

As our analyses of cohorts showed no effect, to test for possible effects of situation on the sibling pair's language choice, we included all the OSBs and all the YSBs. Table 2 exhibits the mean percentage of English-only utterances $(S D)$ of the older and younger siblings in each situation. As can be seen in this table, all situations elicited a majority of English-only utterances. The situation eliciting the lowest use of English was the grandparents (a situation we had classified as Tagalog-oriented) for both the OSBs and the YSBs. The situations eliciting the most English for the OSBs was Christmas (Tagalog-oriented) and school (English-oriented) and for the YSBs Christmas (Tagalog-oriented) and restaurant (English-oriented). We compared all six situations with repeated-measures ANOVAs showing no differences for either the OSBs or the YSBs, $F$ s $<1$. We also tried combining all the Tagalog-oriented situations and all the Englishoriented situations and comparing on a repeated measures ANOVA. Again, the results were not significant for either the OSBs or the YSBs, $F$ s $<1$. Thinking that we might have misclassified Christmas, we reran the same analyses without Christmas and the same pattern of non-significant results emerged.

Table 2 also summarizes the correlation between the percentages of English- 
only utterances by sibling pair in each of the situations. We found strong positive correlations for all of the situations except School. These correlations mean that the more English spoken by one sibling, the more English spoken by the other.

\section{Effect of language choice of experimenters}

To explore potential effects of the experimenters on the language choice of the sibling pairs, we calculated for the mean percentage of English-only utterances of the experimenter, which showed that they did not use English most of the time ( $M=19.0 \%, S D=14.0 \%)$. To see if there was any relationship between the percentage of English utterances used by the experimenters and by the children, we ran Pearson product-moment correlations. There was a strong positive correlation between the percentage of English utterances of the experimenters and that of the OSBs, $r(10)=.61, p<.05$, and a non-significant correlation with that of the YSBs, $r(10)=.38, n s$.

\section{Sibling interactions}

As can be seen in Table 2, there are often high correlations between the percentages of English-only utterances between siblings. These correlations cannot give insight into which sibling (if either) is driving the language choice of the sibling pairs. In this section, we consider some excerpts from the videotaped interactions that might allow some insight into the directionality of language choice.

The example in (1) comes from a PP pair. Here, the OSB names all the people who speak a certain language to her, and in effect, she makes a conscious decision on what she should use to communicate with them. For example, she is aware that, when speaking to her grandmother, (i.e., lola), she should speak Tagalog, using the "only" in the first line suggests that her use of Tagalog is restricted to her communication with her grandmother. This child also claims to consciously choose to speak English with her siblings, a claim that was reflected in her language choice throughout the videotapes.

(1) OSB: My ninang speak English to me. Only to my lola I speak Tagalog.

Experimenter: Eh bakit sa'kin English ka. 'But why do you speak English to me?'

OSB: I speak English to [sibling's name] and [sibling's name].

Experimenter: Hindi kayo nag-Tatagalog sa isa't isa?

'You don't speak Tagalog to each other?'

The example in (1) could indicate that the OSB's language choice is what drives the sibling pair's language choice. The example in (2), however, suggests that it might sometimes be the YSB driving the language choice. The 
example in (2) is from a PS pair. In this example, the OSB asked the experimenter if she could use Tagalog for the conversation, and when the experimenter agreed, she immediately switched to Tagalog with some code mixing. The YSB, however, disagreed with this choice and insisted that English be used considering that other people would be able to see the videos - thus, her use of the word "fans". Later in the same transcript, the YSB corrects the OSB's language choice by saying, "English right? Wag ka Tagalog (Don't use Tagalog)." The OSB used English in her next utterance.

(2) OSB: Pwede mag-Tagalog, A?

'Can I please speak Tagalog?'

Experimenter: Oo naman.

'Yes, of course!'

OSB: Ah, [sibling name], anong [/] anong [//] like favourite like:: pagmagschool ka.

'What do you like? When you go to school?'

YSB: We have to do English right? For the fans.

OSB: Okay.

Experimenter: Kahit ano.

'You can use anything.'

These examples illustrate the patterns we observed across the sibling pairs. Namely, that the sibling driving the sibling-pair's language choice could be either the OSB or the YSB. It was also often unclear if one sibling or the other was really driving the language choice. On the basis of the limited evidence we have here, we conclude that the language choice may be co-constructed by siblings over the course of their interactions and probably over far longer a time period than observed here.

\section{Discussion}

The primary purpose of this study was to explore whether school transition influenced the language choice of Tagalog-English bilingual siblings. We predicted that sibling pairs with at least one school-aged sibling would speak more English (the majority language of the community) than if both siblings were preschool-aged, as has been found in previous research (Bridges \& Hoff, 2014). The effect of school could happen because older siblings' language choice could inform younger ones that the majority of their ambient community speaks English rather than their HL (Mannle \& Tomasello, 1987). In contrast to these predictions, we found that all the sibling pairs, regardless of school-status, spoke more English than Tagalog. One possible reason for these results is that we simply did not have enough statistical power to detect the effect of school transition: indeed, as can be seen by the amount of variance in Figure 1 in the sibling pairs with two preschool children, greater power is 
desirable before reaching firm conclusions. Nonetheless, it was striking that the majority of the sibling pairs, regardless of age and regardless of school attendance spoke mostly English to each other. We will therefore frame our discussion in terms of some possible reasons that the transition to school did not seem to affect these children's language choice below.

A secondary purpose of this study was to test for possible effects of contexts associated with particular languages on the children's language choice. Specifically, we were interested in whether English-oriented situations (i.e., school, store, restaurant) would prompt more English use during sibling interactions than Tagalog-oriented situations (i.e., grandparents, church, Christmas). Given previous results showing that the language choice of sibling pairs can reflect the context (Vihman, 1998), we expected to replicate these results. Contrary to our predictions, our results suggest that all situations elicited mostly English, with no significant differences by orientation.

There are several possible interpretations of this result. One possibility is that context simply does not affect the language choice of these children. Unlike the previous research with two relatively balanced bilingual siblings (Vihman, 1998), this group of children may have been English-dominant early on, making it difficult to use Tagalog. Another possibility is that the contexts we categorized as Tagalog- or English-oriented do not necessarily reflect the children's association of language and context. For example, we had categorized Christmas as Tagalog-oriented since there are some traditional Filipino cultural aspects that families could be celebrating (e.g., Christmas Eve dinners). However, this was one of the situations that elicited the highest use of English from the children. So, it is possible that for these children, Christmas is more strongly associated with Canadian traditions (e.g., snow, gift-giving, Santa Claus) that would signal English use rather than Tagalog. Future studies may wish to garner information about likely language-context associations from parents before carrying out the study. We should note that miscategorization of situations cannot be the entire explanation for the lack of effect: even when we removed Christmas, we still saw the same pattern of null results across situations. A third possible explanation for the lack of effect of context could simply be a question of statistical power. We did find the lowest use of English for the grandparent situation, suggesting that inclusion of a larger number of children could show that context matters. Further suggestive evidence for this view comes from the example given in (1), showing that even a preschool child had conscious knowledge that she only spoke Tagalog with her grandparents.

A fourth possibility for the lack of context effects is that the siblings themselves constitute a context. Previous studies have shown that siblings can choose to speak a language that may not coincide with the parents' preferred 
language choice (Obied, 2009; see also discussion in Caldas \& Caron-Caldas, 2002). Research with preschoolers in Edmonton has also suggested that FrenchEnglish bilingual children are sensitive to the status of English in the community, even in the preschool years (Paradis \& Nicoladis, 2007; see also Chevalier, 2015). So, it could be that even in the preschool years, children can start to become sensitive to the status of the majority language and therefore choose to make that the preferred language of sibling interactions. Future research could compare the social situations of the Spanish-English bilingual children in the US (Bridges \& Hoff, 2014) and the bilingual children in English-majority parts of Canada to see why school transition makes a difference in the former and may not in the latter.

Another factor explaining why the bilingual siblings chose to speak English most of the time is the status of both Tagalog and English in Canada and in the Philippines. The number of Tagalog speakers grew exponentially in Edmonton since the 2006 census such that, currently, it is the most commonly spoken minority language (Statistics Canada, 2013). As the population of Tagalog speakers has only recently undergone such growth, there may simply not have been enough time for programs supporting the use of Tagalog across families (e.g., play groups, preschools, etc.) to emerge. As noted earlier, there are no Tagalog-language schools in Edmonton. The existence of such programs supporting minority language has been shown to help in maintaining the use of HL across generations (Nagpal \& Nicoladis, 2010). Tagalogspeaking families may therefore think Tagalog is not a very useful language to know. English, on the other hand, is an official language in the Philippines, and therefore, has respected status there. Like Singapore, the Philippines offer bilingual education that uses both Tagalog and English as the medium of instruction in school (Daming \& Wei, 2002).

A related factor could be Filipinos' general attitudes toward languages. Given that the Philippines - an archipelago consisting of 7,107 islands - is a linguistically diverse country, it is possible that Filipinos are open to practicing other languages and by extension, of cultures as well. If so, Filipino immigrant families in Canada may be particularly open to Canadian culture and English (see Marks, Szalacha, Lamarre, Boyd, \& Coll, 2007, for results and discussion about the possible role of openness to others). In other words, Filipino immigrants coming to Canada may readily use English because of their own established proficiency and their prior attitudes about language in general and English in particular as a useful language. Indeed, one limitation of the present study is that we had no systematic information about the language that the parents used with their children. In our anecdotal observations, the parents often preferred to speak English with their children. Although some parents talked to us about how they felt it was important that their children could speak the 
HL, many of them were concerned with how well their children would transition to an English-oriented institution - the school. Most parents also cite that even though they watch television shows in Tagalog with their children to promote understanding of the language, they still mostly expose the children to English literature and music, which are more readily available in the community, in order for them to learn English. A future exploration would be to look at the holistic family language background, including language use and resources available to them, to find out the extent to which parents and other unaccounted factors play a role in language choice (Bridges \& Hoff, 2014; Quay \& Montanari, 2016).

The fact that the children in these families use a lot of English could affect their sense of identity later on in life (Noels \& Clément, 2015). One study found that preschool Mexican-American children were able to identify their ethnicity about $80 \%$ of the time, and this correct identification was positively correlated with their Spanish language use (Bernal, Knight, Garza, Ocampo, $\&$ Cota, 1990). Noels and Clément (2015) found that second-generation immigrants (i.e., children of those who first moved to Canada) tend to have more fluid identities between their Canadian and heritage identity, and because of this, their public identity could possibly penetrate intimate domains. In the context of language choice, it could be that when younger siblings have more experience interacting with other cultures different from theirs, then they are more likely to use the language of the public domain in their homes. Similar to our results, the openness of Tagalog-English bilinguals to both their heritage culture and the Canadian culture could explain the predominant use of English even before transitioning to school. However, given that we only accounted for language use but not identity, a future direction would be to test the association between language choice and ethnic identity of these bilingual children later on. Note here that ethnic identity is difficult to examine in the age range that we looked at (i.e., 3-12 years) because according to Eriksen (2001), ethnic identity is not solidified until adolescence. Despite this fact, there is a possibility that language choice could be a precursor to ethnic identity.

In conclusion, the present study examined the language choice between Tagalog-English bilingual sibling pairs. We found that neither the school transition for at least one of the siblings nor the context of conversation significantly affected the children's language choice: most of the children spoke English most of the time. We have speculated about several reasons as to why this pattern of results might have emerged. Immigrant parents may be concerned about the language in which their children will be schooled in, to the detriment of the children's HL proficiency. Some of the parents in this study talked about wanting their children to speak Tagalog. As Nagpal and Nicoladis (2010) pointed out, positive attitudes towards HL use are not enough. 
If families would like their children to speak the HL, then language policies within the home should be explicit and strictly followed in order for younger or later-born children to have more opportunities of practicing their HL (King et al., 2008; Quay \& Montanari, 2016). In a similar way, support from the government and educational institutions becomes crucial in creating programs that promote second language use, whether it has majority or minority language status. A future direction for this study would be to assess whether these bilingual programs (e.g., Tagalog bilingual programs) offered in some schools make a difference in revitalizing language use of passive bilinguals in minority groups. Only by looking at the systems in which bilingual children are growing up, including immediate and extended family (King et al., 2008; Quay \& Montanari, 2016) and the social, cultural and political environment (Beck \& Lam, 2009; Caldas \& Caron-Caldas, 2002; Montanari \& Nicoladis, 2016) will we understand bilingual children's language choice. Clearly, language choice is not only a choice between two languages for bilinguals, but also a choice of "being".

\section{References}

Azmitia, M., \& Hesser, J. (1993). Why siblings are important agents of cognitive development: A comparison of siblings and peers. Child Development, 64, 430-444.

Barron-Hauwaert, S. (2011). Bilingual siblings: Language use in families. Bristol: Multilingual Matters.

Barton, M.E., \& Tomasello, M. (1994). The rest of the family: The role of fathers and siblings in aarly language development. In C.C. Gallaway \& B.C. Richard (Eds.), Input and interaction in language acquisition (pp. 107-134). Cambridge, England: Cambridge University Press.

Beck, D., \& Lam, Y. (2009). Language loss and linguistic suicide: A case study from the Sierra Norte de Puebla, Mexico. Toronto Working Papers in Linguistics, 27, 5-16. Thematic issue: All the things you are: A festschrift for Jack Chambers, S. Cummins, B. Janoski, \& P.A. Shaw (Eds.).

Berko-Gleason, J. (1975). Fathers and other strangers: Their speech to young children. In D. Dato (Ed.), Developmental psycholinguistics: Theory and application, Georgetown University Round Table on Languages and Linguistics (pp. 289-297). Washington, DC: Georgetown University Press.

Bernal, M.E., Knight, G.P., Garza, C.A., Ocampo, K.A., \& Cota, M. K. (1990). The development of ethnic identity in Mexican American children. Hispanic Journal of Behavioral Sciences, 12, 3-24.

Bridges, K., \& Hoff, E. (2014). Older sibling influences on the language environment and language development of toddlers in bilingual homes. Applied Psycholinguistics, 35, 225-241. 
Caldas, S.J., \& Caron-Caldas, S. (2002). A sociolinguistic analysis of the language preferences of adolescent bilinguals: Shifting allegiances and developing identities. Applied Linguistics, 23, 490-514.

Chan, W.H., \& Nicoladis, E. (2010). Predicting two Mandarin-English bilingual children's first 50 words: Effects of frequency and relative exposure in the input. International Journal of Bilingualism, 14, 1-34.

Chevalier, S. (2015). Trilingual language acquisition: Contextual factors influencing active trilingualism in early childhood. Amsterdam: John Benjamins.

Daming, X., \& Wei, L. (2002). Managing multilingualism in Singapore. In L. Wei, M. Dewaele, \& A. Housen (Eds), Opportunities and Challenges of Bilingualism (pp. 275-296). Berlin: Mouton de Gruyter.

Deuchar, M., \& Quay, S. (2001). Bilingual acquisition: Theoretical implications of a case study. Oxford: Oxford University Press.

Dunn, J. (1983). Sibling relationships in early childhood. Child Development, 54, 787811.

Eriksen, T.H. (2001). Ethnic identity, national identity and intergroup conflict: The significance of personal experiences. In R.D. Ashmore, L. Jussim, \& D. Wilder (Eds.), Social identity, intergroup conflict and conflict reduction (pp. 42-70). Oxford: Oxford University Press.

Fantini, A. (1985). Language acquisition of a bilingual child: A sociolinguistic perspective. San Diego: College Hill Press.

Genesee, F., Boivin, I., \& Nicoladis, E. (1996). Talking with strangers: A study of bilingual communicative competence. Applied Psycholinguistics, 17, 427-442.

Genesee, F., Nicoladis, E., \& Paradis, J. (1995). Language differentiation in early bilingual development. Journal of Child Language, 22, 611-631.

Gregory, E. (2001). Sisters and brothers as language and literacy teachers: Synergy between siblings playing and working together. Journal of Early Childhood Literacy, $1,301-322$.

Grosjean, F. (2016). The Complementarity Principle and its impact on processing, acquisition, and dominance. In C. Silva-Corvalán \& J. Treffers-Daller (Eds.), Language dominance in bilinguals: Issues of measurement and operationalization. Cambridge: Cambridge University Press.

Hoff, E. (2006). How social contexts support and shape language development. Developmental Review, 26, 55-88.

Hoff, E. (2003). The specificity of environmental influence: Socioeconomic status affects early vocabulary development via maternal speech. Child Development, 74, 1368-1378.

Hughes, C., \& Dunn, J. (2007). Children's relationships with other children. In C.A. Brownell \& C.B. Kopp (Eds.), Socioemotional development in the toddler years: Transitions \& transformations (pp. 177-200). New York: Guilford Press. 
Huttenlocher, J., Vasilyeva, M., Waterfall, H.R., Vevea, J.L., \& Hedges, L.V. (2007). The varieties of speech to young children. Developmental Psychology, 43, 10621083.

Jia, G., Chen, J., Kim, H.Y., Chan, P.-S., \& Jeung, C. (2014). Bilingual lexical skills of school-age children with Chinese and Korean heritage languages in the United States. International Journal of Behavioral Developmen, 38, 350-358.

King, K.A., Fogle, L., \& Logan-Terry, A. (2008). Family language policy. Language and Linguistics Compass, 2, 907-922.

Kopeliovich, S. (2013). Happylingual: A family project for enhancing and balancing multilingual development. In M. Schwartz \& A. Verschik (Eds.), Successful family language policy: Parents, children and educators in interaction (pp. 249-275). Dordrecht: Springer.

Marks, A.K., Szalacha, L.S., Lamarre, M., Boyd, M.J., \& Coll, C. (2007). Emerging ethnic identity and its relation to social group preferences in middle childhood: Findings from the Children of Immigrants Development in Context (CIDC) study. International Journal of Behavioral Development, 31, 501-513.

Mannle, S., \& Tomasello, M. (1987). Fathers, siblings and the bridge hypotheses. In K.E. Nelson \& A. van Kleeck (Eds.), Children's language (Vol. VI, pp. 23-41). Hillsdale, NJ: Lawrence Erlbaum.

McHale, S., Updegraff, K., \& Whiteman, S. (2012). Sibling relationships and influences in childhood and adolescence. Journal of Marriage and Family, 74, 913-930. doi: 10.1111/j.1741-3737.2012.01011.x

Montanari, S., \& Nicoladis, E. (2016). Concluding remarks and future directions. In E. Nicoladis \& S. Montanari (Eds.), Bilingualism across the lifespan (pp. 325330). Washington, DC: De Gruyter Mouton and the American Psychological Association.

Nagpal, J., \& Nicoladis, E. (2010). Positive attitudes are not enough: Minority language survival in the Canadian Prairies. Journal of Intercultural Communication, 24. Available at: immi.se/intercultural/nr24/nagpal.htm

Noels, K.A., \& Clément, R. (2015). Situational variations in ethnic identity across immigration generations: Implications for acculturative change and cross-cultural adaptation. International Journal of Psychology, 50, 451-462.

Obied, V. (2009). How do siblings shape the language environment of bilingual families? International Journal of Bilingual Education and Bilingualism, 12, 705-720.

Parada, M. (2013). Sibling variation and family language policy: The role of birth order in the Spanish proficiency and first names of second-generation Latinos. Journal of Language, Identity \& Education, 12, 299-320,

Paradis, J., \& Nicoladis, E. (2007). The influence of dominance and sociolinguistic context on bilingual preschoolers' language choice. International Journal of Bilingual Education and Bilingualism, 10, 277-297. 
Quay, S., \& Montanari, S. (2016). Early bilingualism: From differentiation to the impact of family language practices. In E. Nicoladis \& S. Montanari (Eds.), Bilingualism across the lifespan (pp. 23-42). Washington, DC: De Gruyter Mouton and the American Psychological Association.

Statistics Canada (2013). Alberta: Immigrant and ethnocultural diversity. (Catalogue no. 99-010-XWE2011005). Ottawa, ON: Statistics Canada. 2011 Census, NHS [National Household Survey] Focus on Geography series. Retrieved from: www12. statcan.gc.ca/nhs-enm/2011/as-sa/fogs-spg/Pages/FOG.cfm?lang=E\&level=2\&Geo Code $=48 \#$ tabs $1 \_7$.

Vihman, M. (1998). A developmental perspective on codeswitching: Conversations between a pair of bilingual siblings. International Journal of Bilingualism, 2, 45-84.

Yan, S., \& Nicoladis, E. (2009). Finding le mot juste: Differences between bilingual and monolingual children's lexical access in comprehension and production. Bilingualism: Language and Cognition, 12, 323-335. 